\title{
A Review for Embedding Human Dimension of Sustainability to Maintain Energetic Organizations in Egypt
}

\author{
Randa El Bedawy ${ }^{1}$ \\ ${ }^{1}$ Misr International University, Egypt \\ Correspondence: Randa El Bedawy, Faculty of Business Administration and International Trade, Misr \\ International University, Egypt. E-mail: randa.bedawy@miuegypt.edu.eg
}

\author{
Received: January 19, 2015 Accepted: February 9, 2015 Online Published: February 20, 2015 \\ doi:10.5539/jms.v5n1p158 URL: http://dx.doi.org/10.5539/jms.v5n1p158
}

\begin{abstract}
There is a remarkable interest from both public and private sectors for supporting and sustaining energetic organizations that have the ability to be creative and productive over time. However, there is still a limited attention on the human dimension of sustainability compared to the economic and environmental dimensions. Human energy is in fact a crucial dimension of human sustainability to maintain energetic organizations but human energy can also be depleted if it is not well managed. The significance of this study lies in the fact that human sustainability constitutes a real crisis in most organizations in Egypt, affecting employees' performance and productivity, an issue which has been of a major concern ever since the $25^{\text {th }}$ January Revolution. Accordingly, this study responds to a significant call for a greater understanding of human sustainability at work. Since the concept of human energy is still limited researched, this study intends to highlight the core of human dimension of sustainability by exploring the strategies that individuals use at work to manage and to sustain their energy throughout the workday. This study intends to recommend strategies for embedding human dimension of sustainability to maintain energetic organizations. Moreover this study opens a new area of research in organizations that will be rewarding for understanding the sustainability of employees' energy at work as well as the sustainability of organizations as a whole on the long term. This study can also provide a good starting point for human resource management HRM professionals to provide a display of HRM functions that are required to support human dimension of sustainability to maintain energetic organizations. The study concludes that maintaining energetic organizations in Egypt requires a comprehensive strategy for embedding human dimension of sustainability through an effective human energy management as the ability of employees to manage their energy at work is one of the important factor for supporting their productivity and welfare.
\end{abstract}

Keywords: human energy crisis, human energy management, human resource management, human sustainability, work motivation

\section{Introduction}

A continuous and central concern for both the public and the private sectors is the success of their organizations, which is mainly determined by the productivity of its employees as well as the satisfaction that their employees derive from their jobs. However, there is always the problem of a proper identification of the reward system that should be really valued and appreciated by the employees. The question is always related to the reward mix either to be intrinsic or extrinsic and whether to be financial or non financial. The aim is continuously to design the adequate reward mix, which can lead to the employees' motivation and satisfaction. The problem is much more visible in public organizations in Egypt. Although the public administrators are often overworked, underpaid and underappreciated, their 'Public Service Ethic' is important because it roots the assumption that public servants are self motivated by protecting and working for the good of the public. However, there is a much doubt about whether this ideology can apply generally to developing countries and specifically to the Egyptian public administration context. As always discussing the bad performance of the public sector in Egypt, mainly characterized by the bureaucracy and the lack of work motivation for the public administrator, the blame is always directed to the limited financial resources available which can be relatively true, although most of the literature on motivation gives more weight to the intrinsic rewards in the work, more than other extrinsic rewards as the financial resources. The significance of the study lies in the fact that human sustainability constitute a real crisis in most public organizations in Egypt affecting employees' performance and productivity, an issue which 
has been of a major concern ever since the $25^{\text {th }}$ January Revolution. Accordingly, there is a significant call for a greater understanding of human sustainability at work by examining strategies that employees use to manage and to sustain their energy throughout the workday. Then it is crucial to recommend strategies for embedding human dimension of sustainability to maintain energetic organizations in Egypt. Recent research on the management of organizations has highlighted the need for remarkable measures when handling employee issues and organizations. However, there has been relatively little attention on how they might influence the development of sustainable and effective management of organizations and employees (Schiuma, 2011).

By analyzing the definitions and the evolving concepts of human resource management over time, it can be noticed that the attention to human resource has changed radically. The investment in human resource is perceived nowadays as a strategic approach to be continuously optimized and not as costs to be minimized (Anca, 2009). Although the crucial and the apparent need for HRM involvement in sustainability initiatives, it does not offer a model to guide strategic HRM leadership in organizational sustainability initiatives (Dubois, 2012). According to Spreitzer (2011), although human energy is a critical resource that supports organizations to run profitably, yet we generally fail to manage it effectively, which in turn leading to lower productivity and employees' dissatisfaction (Spreitzer, 2011). Top Management generally perceives managing sustainability as critical to their company's effectiveness (Kell \& Lacy, 2010). Accordingly the strategic roles played by HRM expanded over the past few decades, adding to the increased expectations that the HRM function should provide an added value to the firm (Dubois, 2012). Since companies committed to sustainability outperformed industry averages during the financial crisis (A.T. Kearney, 2009), then addressing sustainability challenges can create much more shareholder value. However, the human resource management literatures have lacked an influential voice in sustainability circles (Hart \& Milstein, 2003). Recently, there are increasing calls for a better understanding of the human dimension of sustainability. Responding to this call, this study intends to explore how individuals sustain an important human resource as their own energy at work. Specifically, this study focuses on strategies that employees can use to sustain their energy.

This study is an exploratory investigation of the role and relevance of human energy to create and maintain energetic organizations. The study examines the sources and dynamics of energy, in order to provide insights into the nature of energetic organizations and how they can leverage the concept of energy to improve business performance. In fact organizational energy is dynamic in nature as it is more than just the sum of the energy of its employees as it also includes the interface and dynamics of teams and the organization as a whole. This study shines a light on the idea of human sustainability that may have important implications for work organizations (Fritz, 2011). Moreover, this study opens a new domain of research in organizations that will be crucial for maintaining the sustainability of employees' energy at work as well as the sustainability of organizations as a whole on the long term. Although not necessarily that everyone wants to become a high achiever or a top performer, yet, this research intends to clarify how one can stay energized while reaching the goals in work and life (Schippers, 2011).

Since the energy of employees is recognized as an important factor for maximizing their overall contribution to the organization and also to respond to an emerging call for a greater understanding of human sustainability at work, this qualitative study is an exploratory investigation of the role and the relevance of human dimension of sustainability in driving business performance. In order to provide insights into what constitute an energetic organization, this study sheds the light on the nature of human energy at work as a core dimension of human sustainability. To explore the relationship between human dimension of sustainability, energetic workforce and business performance, this study intends to answer three sets of research questions:

- What effect do energetic human resources have on organizations?

- What are the factors that play a role in energizing human resources?

- How organizations can leverage the concept of human dimension of sustainability to improve business performance?

\section{Literature Review}

\subsection{Human Energy as Human Dimension of Sustainability in Organizations}

Several approaches to sustainability confirm the relevance of human component to build the environment, yet few practices based on this concept have been implemented as sustainability is generally addressed to the evaluation of natural resources consumption in the building lifecycle (Attaianese, 2012). In fact, embedding environmental sustainability ES deeply into an organization requires changes in thinking and behavior across all levels of employees in all areas and levels of an organization such as the participation of every employee in 
recycling, or turning off equipment and lights that aren't requested. Actually when ES is truly embedded within an organization, it infuses the thinking and behavior of employees to go beyond compliance with rules or norms but even to participate in innovating changes in work processes (Laszlo \& Zhexembayeva, 2011).That's why managing human energy is particularly challenging, and it is requiring HRM systems that are consistently aligned to clarify and support organizational ES goals to align their employees' actions and their energy with organizational ES goals. Accordingly, HRM systems can play a main role in embedding ES throughout an organization through setting an effective human energy management (Dubois, 2012).

Some employees at the workplace seem spreading their passion as they go and they are obsessed by work as being workaholics. Actually, an important factor in their success is their energy which is not just their physical strength or stamina or their mental capacity, as energy drives motivation, promotes creativity and in turn creates competitive advantage for the organization (Schiuma, 2011). Spreitzer finding (2011) argues the concerns regarding the lack of understanding about human sustainability. If employees cannot sustain their energy over longer periods of time, organizations cannot expect them to maintain a high level of performance (Spreitzer, 2011). Human Energy is a key factor affecting organizational performance and the more energy an employee has, the more effort the employee will be able to put into their work as human energy is connected to individual and team performance, adding to the innovation and job satisfaction.

\subsubsection{Defining Human Energy at Work}

First of all, what is human energy at work? The word energy is derived from the Greek words 'energeia', reflecting the activity or the operation (Harper, 2001). As Taylor \& Casey (2011) noted, the sustainability of an organization depends upon its ability to maintain the contributions of its human resource energy. Moreover, Energy can be defined as a type of positive affective arousal, which people can experience as emotion or mood (Taylor, 2012). According to Schippers (2011), people can be completely focused and energetic in all domains as sports, games, hobbies, or work. The Chambers English dictionary defines energy as 'the capacity for vigorous activity, liveliness or vitality', 'force or forcefulness', or 'the capacity to do work'. This definition is basically reflecting the physical energy but it also can help to understand HR energy within organizations (Schiuma, 2011). Energy can also be reflected in terms of the energy around a project or people inside the organization to describe energetic people or groups (Cross et al., 2003).

According to Frijda (1988), energy can swing between energizing and de-energizing as well as it can be created or destroyed. Loehr and Schwartz $(2001,2003)$ simply define energy as the capacity to do work that allows us to perform physical, mental or emotional tasks (Schiuma, 2011). Moreover, according to Fritz (2011), human energy is an affective or a reinforcing experience that people enjoy or seek and it is reflected by vitality or lack of fatigue. Vitality reflects a feeling of being enthusiastic or alive. Thus, human energy stimulates organizations to achieve successfully (Fritz, 2011). Energy could be measured by asking people what kind of work gives them most satisfaction, how often they perform these tasks, how well they achieve their goals, and how much time they spend on recovery from work (Schippers, 2011). As noticed, there are so many definitions and perspectives of 'Human Energy'. Actually, researchers seeking to learn more find it very challenging in research of human energy and its relationship to workplace (Taylor, 2012). Even when scholars use similar definitions, they often make different assumptions about how energy works, such as whether it is a scarce resource or an abundant one. Understanding these definitions and assumptions is crucial if practitioners want to be well informed for making decisions about what role energy does for the effective operation of organizational activities. Ultimately, the clarification and integration of all the definitions of human energy is necessary to enhance understanding of some of organizational behavior's topics. A review on human energy reveals that sometimes definitions of energy are not clear. As a result, scholars may use different terms to mean something similar or the same terms to mean different things (Quinn, 2012).

\subsubsection{Human Energy Dimensions, Levels and Types in Organizations}

Human Energy is a crucial but limited resource that can foster high performance in organizations. Accordingly, it is necessary to maintain an optimal energy level. In this respect, three kinds of energy are often distinguished. First is the mental energy as being able to intensely focus; second is the physical energy as strength or stamina and third is the emotional energy as being in touch with one's own emotions. According to Schippers (2011), within the energy dimensions, three characteristics of energy can be discerned as the amount, the stability, and the direction of the energy. For example, when a person has a high amount of mental energy, but stability and direction are low, then this person can focus intensely on a task, but only for a short period of time and without much direction. Research in human energy management reflecting that having a lot of physical energy cannot guarantee success when the stability of energy is not in order. Regardless the amount of energy, without 
direction of energy, the problems will occur if the energy is not linked to targets. Energizers usually have a vision and are able to convince others to work towards it but de-energizers represent the black holes which draining the energy of their co-workers and leaders (Schippers, 2011). According to Bruch and Ghoshal (2003), the energy level can be evaluated based on two main variables 'intensity and quality'. Intensity refers to the strength of organizational energy and it can be revealed in the number of activities performed or the extent of alertness and emotional excitement. Quality represents the impact of the energy on the task or objective achievement. Organizational energy should be channeled in order to drive successfully the organizational performance (Schiuma, 2011).The energy level and energy states are closely related, but while energy level relates to the amount of energy, the energy state relates to the nature of that energy. An energy state determines the quality of a person's experience or the state of well being and happiness (Quinn and Dutton, 2005, Ryan and Frederick, 1997). Energy states reflect how much effort an individual or team is willing or able to invest. Generally, people who feel positive levels of energy tend to perceive or expect that positive events will occur and will invest much more effort to achieve their objectives. It involves aspects such as the emotional excitement, alertness or creativity as well as enthusiasm and satisfaction (Schiuma, 2011). According to Srinivasan (2012), the core of efficient energy management is based on plugging the individual human energy to the universal energy as most of us do not know how to receive energy from universal sources as we normally receive it from limited sources as food or relationship. However, we are not fully conscious about the other sources of energy in our daily life such as interactions with people which involve an exchange of vital energy (Srinivasan, 2012). Schiuma's study reflected that there are three types of energy. First is the individual energy "Energetic individuals are Passionate individuals", second is the team energy "Sparks between individuals generate team energy", and third is the organizational energy "Individual, group and social network energy". Although these different types of energy clearly exist, they are not explicitly separated into these categories in the literature. Schiuma believes that organizational energy is related to the sum of the energies of all the employees, plus the sum of the social network energy created within and between teams. Accordingly, the evolving energy is the outcome of synergetic integration of all the forms of energy (Schiuma, 2011). Then when considering energy at work, it is important to clearly differentiate between the types of energy because they should be managed differently.

\subsection{Understanding How Energy Drives Performance in Organizations}

\subsubsection{Motivation}

Motivational force can be defined as the amount of effort expended to perform a task and it can be assessed as the amount of physical and physiological effort expended in performing a task (Schiuma, 2011). Clearly, motivation and energy are interrelated. However, energy is a necessary condition, but is not sufficient to determine motivation. Hence, motivation needs energy to be realized. In this regard, Steers (2004) highlights that all of the main definitions of motivation are primarily concerned with the factors that energize, channel and sustain human behaviour over time. In this context energy is a fundamental component of motivation and energy can be considered as the engine of motivation as it affects both the direction in which a person chooses to act and the effort a person invests. In addition, energy determines the perception of the attractiveness of various alternatives. Energy also represents a good indicator to predict whether an individual will achieve results, as people tend to invest as much effort into activities as they feel they have energy to exploit (Collins, 1981). Moreover energy can increase expectancy of high results and rewards. In fact, some researchers equate energy with motivation or see energy as the key resource in the motivation process. However, motivation is generally can be perceived as an umbrella that encompasses the initiation, direction, intensity, persistence, and termination of effort (Quinn, 2012).

\subsubsection{Leadership}

It is a leadership task to define an appropriate vision and strategy which play a fundamental role in creating an energetic organization. They define the mode of energy management and provide drivers for guiding organization' energies toward the common goals. It is the task of leadership to set an appropriate vision and strategy to unleash the organizational energy in order to capture people's emotional, intellectual and physical capacities for supporting key strategic goals (Schiuma, 2011).

\subsubsection{Environment}

The external environment affects the organization in many different ways. Then, it is the role of management to scan the environment for opportunities and threats and use this information to refine the strategy in order to transmit information to its employees, the way in which this can affect employees' energy based on the culture and communication styles of the managers. Taking into consideration that the environment is multifaceted for 
employees as the environment in which each employee exists is different to that in which the organization exists. For example, employees' personal environments can include home life, past times or relationships and actually each of these can affect the employees' energies in many different ways (Schiuma, 2011).

\subsection{Depletion of Human Energy at Work}

Employees generally are requested to do a variety of tasks during the workday but actually the fulfillment of most of these tasks requires human energy and effort. Thus, employees need energy not only to accomplish their daily work tasks but also to go beyond what they are required to do. Accordingly, human energy can be considered as a resource that supports people to control their behaviors and emotions in order to comply with organizational norms and expectations. However, this energy as a resource can be depleted over time due to excessive work demands. Thus, employees need to find different ways to replenish their energy on a regular and continuous basis (Fritz, 2011).

\subsubsection{Human Energy Crisis}

Human energy is like a battery that can be depleted over time if not well regularly recharged. Actually the depletion of human energy at work can be called as human energy crisis that must not be ignored (Spreitzer, 2011). In fact lots of employees are generally feeling overworked, or pressured to the point of depression or disease. This problem is getting worse because of the increased aggressive competition, dynamic market changes, adding to the continuous terrible news such as natural disasters or terrorism (Spreitzer, 2011). The complaint of modern times is that we are usually busy all the time. However, we are actually wasting a lot of time instead of doing what we really need or want to do. A lack of energy can also be perceived as an emotional dissonance as reflecting a conflict between real feelings or required shown feelings. In jobs requiring lots of emotional labor, human energy can be drained quickly (Schippers, 2011). The researchers confirm that the energy loss is a perceived lack of personal control. In contrast, successful managers were usually the ones who did take initiative and acted on opportunities. Those managers were able to focus their energy in a proactive way and they did not get diverted by any kind of distractions. Accordingly workers, who use most efficiently their time, will also be able to use their energy much more effectively (Schippers, 2011).

\subsubsection{Forces Draining Human Energy at Work}

Human energy helps employees to regulate their behaviors and emotions in order to meet organizational performance expectations. However, energetic resources are limited and can be depleted over time which increases stress or leads to burnout and definitely will weaken the overall organizational performance (Spreitzer, 2011).There are many factors that contribute to the depletion of human energy at work such as the long working hours. For example, lots of employees are obligated to respond to calls and emails outside of normal work hours. Moreover, as organizations are currently more fighting for financial survival, they are in turn less able to afford perks such as fitness facilities, additional vacation days or free food that can support reenergizing employees. The job insecurity can also bring a sense of uncertainty that makes employees unwilling to take time off for their recovery and their worries can lead to their sleeping disruption or higher levels of fatigue during their workday. The need for interpersonal interaction and coordination at the workplace is also increased because jobs have become more interdependent. However, this interaction and coordination require also an effort and thus it can also drain human energy. In addition, there are also factors that are beyond one's immediate work environment that can deplete human energy at workplace. For example, the number of single parents is growing, and in turn the employees are less likely to have a partner for taking care of home life. Accordingly, employees have less time for recovery during leisure time as they have another second shift of housework and childcare when they finish their workday (Fritz, 2011). Actually, the human energy crisis often gets worse during recessionary times as the workloads increase usually because of layoffs. In turn, Spreitzer (2011) identifies four key levers for energy management. First is 'physical' to build fitness; second is 'mental' to create focus and attention; third is 'emotional' to enable excitement and connection; and fourth is the 'spiritual' to provide centeredness. These four key levers for energy management can be viewed as a kind of pyramid where physical energy forms the foundation for mental energy, which forms the foundation for emotional energy, which in turn is the foundation for spiritual energy (Spreitzer, 2011). Given that so many factors can deplete human energy at work, so it is really important to consider how employees can generate more energy and reduce fatigue at work in order to maintain energetic organizations. Regardless of the environment that they are embedded in, it is actually crucial to support the employees as well as the leaders to learn how to recharge their energy through recognizing the drastic costs of energy depleting behaviors, then also taking their responsibility to be energy producing or conserving. To this end, this study introduces a tool that can help them manage their energy to be healthy and productive in their personal as well as their professional lives. 
In the next sections, the study tends to explore how then can we make sure to be energized and to energize others as well as what are the factors that play a key role in energizing or de-energizing others.

\subsection{Effective Human Energy Management}

Energetic employees are people with a lot of energy and they are in turn more productive, creative and usually have a good positive influence on others as employees stimulate each other which also for sure positive for maintaining energetic organizations. Everything generally seems to happen much easier when there is a high energy level in the organization (Schippers, 2011). However, we are generally required to do much more and the demands on our energy exceed our capacity, in turn resulting in lower productivity and unfulfilling relationships. Actually, although energy is our most critical resource, most of us still fail to manage it efficiently and effectively. Therefore under pressure, we must be trained in all dimensions 'physical, mental, emotional and spiritual' to manage our energy effectively in order to improve our performance (Srinivasan, 2012).

\subsubsection{Management of Human Energy: Principles}

The first principle is that 'energy cannot be stored indefinitely' and it has to be used in a creative and productive way to become ready to acquire more energy. Actually, when energy is not used properly, it can cause fatigue or disturbance. Then, both overworking as well as laziness can lead to fatigue. Accordingly we should learn how to receive, maintain and spend energy in the right way. The second principle is 'calm and peace' and this is really essential for receiving as well as maintaining energy as not much of energy can be received when we are in a state of anxiety. The third principle is 'wideness' as we cannot receive much if we just live in the narrow borders of our personal self-interests or just our physical desires. The fourth principle is 'self-giving and generosity' as the ability to lose little ego can bring us easier into a contact with different universal forces (Srinivasan, 2012). Another important principle in human energy management is also to eliminate or minimize any wasteful inner or outer movements which can drain energy. According to Srinivasan (2012), the elimination of waste is now an established principle and practice in the human energy management. The factors which can lead to waste of energy are many and varied such as the restlessness of body or mind; and conflicts or quarrels. Repetitive and negative feelings like anger or jealously can also drain energy. Accordingly there is a need for self control and actually all these factors which can waste energy have to be maintained under control for human energy conservation. Moreover, concentration is crucial to focus the energies in a single point to help in conserving energy. Then, as a compelling factor, human energy management requires the combination of inner calm, concentration and self-control (Srinivasan, 2012).

\subsubsection{Management of Human Energy: Off Work Recovery Processes}

Organizations cannot maintain nor achieve high-level performance as long as employees cannot maintain their energy over longer periods of time. Thus, in this study, it is crucial to shed the light on how recovery can take place at work or outside work. Employees generally are required to fulfill a variety of tasks during their workday but unfortunately the fulfillment of most of these tasks requires lots of human energy. Actually, employees need their energy not only to carry their regular daily work tasks but also to go beyond what they are just required to do. Thus, employees need urgently to find different ways to replenish their energy on a regular basis. Research on recovery has found that employees can use their time off work such as evenings or weekends to recharge their energy and reduce their fatigue. For example, Fritz (2011) found that recovery experiences during the weekend were positively related to joviality which is an experience similar to human energy as well as to lower levels of fatigue. Further, Fritz (2011) argued that recovering from work stress during the evening was related to higher levels of work engagement at the next workday. Research also supports that employees' experiences during their non work time is an important affair to restore human energy as well. For example, experiences such as relaxation or psychological detachment from work have been found to be specifically beneficial for recovery. Moreover, sleep is also an important factor for replenishing human energy as the employees experiencing a high quality of sleep at night reported generally higher levels of energy at the next work day (Fritz, 2011). Although the remarkable tendency for better understanding of what replenishes energy during off work time, research indicates that the beneficial effects of recovery during off work time weaken over time. For example, within few weeks after vacation, the positive vacation effects tend to weaken and stress levels usually return to their original levels. Research on recovery from work demands provides some ideas regarding how employees can manage their energy. With the need for recovery, many companies nowadays offer variety of workplace wellness programs that can include help with exercise, or stress management (Spreitzer, 2011). While smoking and coffee breaks at work were found to be harmful to health, the rest breaks and physical activity during breaks were found to be more beneficial. For example, regular ten minute breaks decreased fatigue, anger, depression as well as it improved the mood (Fritz, 2011). 


\subsubsection{Management of Human Energy: Work Related Strategies}

The goal of this study is to explore variety of work related strategies that employees can use to manage their energy at work. According to Fritz (2011), there are four strategies related to the management of human energy at work. First is the 'physical strategies' that usually reflect the form of a break to perform basic physiological needs such as drinking water or engaging in any kind of physical activity. Second is the 'relational strategies' that reflect connecting with people in a positive manner such as to offer help to someone. Third is the 'mental strategies' that reflect tending to be focused such as making a to-do list for work. Finally is the 'spiritual strategies' that reflect perceiving a bigger picture of things such as thinking about a meaning for one's work or life. Some of these strategies can be called "micro breaks" as they aren't directly related to the doing of work such as drinking water or having a snack. On the other hand, some other strategies are more centered on how employees do their work and it can be called as "work-related strategies" because they take place during the doing of work such as switching to another task or making a to-do list. Other strategies such as going outside for fresh air or being close to nature were neither related to vitality nor to fatigue. Although these strategies were discussed, it is still not clear nor confirmed that they are the most effective ways to manage human energy at workplace (Fritz, 2011). On the other hand, the strategies that were found to be mostly related to vitality are 'learning oriented' as learning something new, 'relational' as doing something that will make a colleague happy, and 'meaning-related' as reflecting on how might make a difference at work. Actually there is a strong relationship between learning and energy as when people are learning, they are also developing which in turn creates psychological resources and they also become open to new things and changes, all of which increase energy. Moreover, positive relationships at work are energizing at both the physical and the emotional levels. In contrast, bad work relationships can deplete psychological resources. Then human energy and the quality of connections with others at work seem to be really crucial to be considered (Fritz, 2011). Moreover, managing human energy requires managing energy dynamics in organizations such as organizational infrastructure, social interaction and individual behavior as their functioning and interactions dictate the organization's energy conditions in terms of level and states. There are generally basic recommended strategies for renewing energy at the physical level such as eat a balanced diet; get physically active; go to bed early or wake up early (Schiuma, 2011).

\subsection{The Energy Resource Manager: What Could Their Goals Be? What Could They Do? Who Could It Be?}

All members of the organization should drive energy management as part of their working and personal lives. An emotional expression as feeling happiness can be considered an approach for transferring energy inside the organization as it was noted that organizations may waste employees' energy through a variety of detachment behaviors. In fact, infrastructure can be also considered as a mechanism that stimulates energy creation in organizations and it can include both tangible and intangible dimensions that can be intentionally designed to stimulate and drive energy in the organization. The tangible factors may be colored, bright or well designed rooms (Schiuma, 2011). However, the intangible organizational infrastructure includes recruitment, selection and HRM practices, adding to the organizational culture and performance measurement systems, all of which represent a powerful approach for driving individual and organizational behaviors. HR managers generally are looking for employees who can bring energy to their organizations. Moreover, HR managers are also responsible to drive individual and team dynamics as well as to monitor the level of energy within the organization. HR managers can adopt interviews; questionnaires or psychological instruments to expose the quality and intensity of energy at work (Lounsbury, 2004). Accordingly, the HR manager clearly holds a key for HR energy management through recruitment and selection processes as well as through the general HR practices (Schiuma, 2011). Then the work of the HR manager is essentially to focus the HR energy in the organization to achieve its strategic goals, including the goal of enhancing organizational learning. For the HR manager, a strategic factor for success in fulfilling the goals of the organization is to produce and maintain HR energy (Taylor, 2012). Accordingly to maintain energetic organizations, an 'Energy Resource Manager' in many organizations should emerge to initiate and coordinate HR energy management programs. An Energy Resource Manager should focus and guide the organization energy to support key organization strategic goals and also should be responsible to implement initiatives aimed to stimulate and activate energy (Schiuma, 2011).The goal of 'Energy Resource Manager' is to embed human energy management in daily organizational life; develop awareness within the organization about the urgency of human energy management. The 'Energy Resource Manager' is also responsible to drive people, teams and the organization to force energy requested for business development. Moreover, the 'Energy Resource Manager' should be able to create the appropriate energy levels in order to adjust and adapt with the various contingent competitive environment in terms of threats or opportunities. The 'Energy Resource Manager' should then spend a lot of time meeting and speaking with people in order to 
understand people's feelings and energy and in order to be able to distinguish between 'energizers' and 'de-energizers'. According to Schiuma (2011), the two basic competencies requested for the 'Energy Resource Manager' are being as psychologists and coaches as should be able to manage the emotional facets of employees, as well as to guide them as organizational athletes. 'Energy Resource Manager' should create a social environment that arouses the social interactions requested for energy creation. Important dimensions of 'Energy Resource Manager' personality traits are being extroversion, openness, agreeableness and conscientiousness. Accordingly, appointing an 'Energy Resource Manager' may be a good start for embarking the human energy management program inside the organization. However, it is unlikely to be sufficient in itself because what is really necessary is that energy management becomes embedded in organizational culture, recognizing its crucial role as a source for employees' motivation and increased productivity, which in turn can force both value creation and competitiveness for the organization.

\section{Concluding Remarks and Recommendations}

Over the past 20 years, public and business interest in sustainability has radically increased but still much of the focus has been only on its environmental and economic dimensions and much less on the human dimension. Although reducing waste and increasing focus on the natural environment are basic features of sustainability, it is also crucial to develop a better understanding of the human dimension of sustainability, particularly in terms of energy and health. Human sustainability constitute a real crisis in most organizations in Egypt affecting employees' performance and productivity, an issue which has been of a major concern ever since the $25^{\text {th }}$ January Revolution. This study further develops the idea of human sustainability by introducing a tool that can be used to help employees manage their energy in order to be healthy and productive in their personal and professional lives. Actually, the more we can support employees for developing their energy at workplace, the better we can also help them to sustain their energy for high performance for a lifetime (Spreitzer, 2011). In practice, people should become aware of the things that are energizing to them and to capitalize on them more regularly. It is noted that high quality relationships at work generate and sustain energetic resources, equipping people to do work well. Accordingly, good interactions with others are basically related to be more energized at work and individuals who were able to energize others, are actually reflecting a higher job performance themselves. Moreover, strategies that give the opportunity to learn and grow seem to be necessary for human energy management. The study also offers specific approaches guiding how people seek to manage their energy at work. The study confirms as well the importance of the intrinsic factors in work motivation. In specific, strategies reflecting on how work is meaningful, what gives joy or where one can make a difference, are related to drive employee energy at the workplace. Further, the study focus on strategies that employees can self initiate to manage their energy and to be more energy sustaining over time. Then what matters most for managing human energy at work are basically strategies that employees are practicing for doing their work. Specifically, job designs with high level of autonomy, can give employees the opportunity to maintain their psychological resources (Fritz, 2011). Energy in organizations is a key driver of business performance, yet energy is dynamic in nature and changes continuously over time. As energy needs to be created, sustained and not to be destroyed, then the appointment of the 'Energy Resource Manager' is one way to support building energetic organizations.

Maintaining energetic organizations in Egypt requires a comprehensive strategy for embedding human dimension of sustainability through an effective human energy management as the ability of employees to manage their energy at work is one of the important factor for supporting their productivity and welfare. Within the limitations and the challenges of the business environment in Egypt, as practical tools that help in managing human energy at the workplace and for creating energetic organizations in Egypt, three main practices are recommended. First, it is important to plan according to result areas instead of random actions. Successful energetic workers are capable of making important things and make sure to spend their time on these tasks on a daily basis. It is much more efficient and effective to do a few big things within the result areas than do a lot of small things without a direct measurable consequence as workers usually lose energy because of time they need to refocus their attention. Second, it is essential to determine long term goals as an important prerequisite for effective energy management. If organizations are capable to make parameters to measure progress toward long term goals, then this will have a powerful drive for workers to really act upon their main organizational goals on a daily basis. Third, it is crucial to maintain physical fitness in order to maintain energy on the long term especially when one has a desk-job. It is also important to make exercising as a top priority. Usually stress is a main cause of burn out or diseases, then it will surely help to increase awareness about the direct link between physical fitness and stress reduction for staying energized at work. It is relatively easy to integrate physical activity into daily life, by walking or cycling to work or including active tasks into everyday life. Actually supporting awareness about the physical fitness through walking or cycling to work can be very beneficial 
especially in Egypt, not only for embedding human dimension of sustainability or human energy management but it is also crucial to handle the drastic traffic problem in Egypt.

In sum, the study sheds the light on the importance of understanding how employees can successfully sustain high levels of human energy over time which would in turn underline the importance of human dimension of sustainability to maintain energetic organizations. At the end, the human energy management strategies are various and can be embedded inside organizations to preserve human sustainability as well as to sustain energetic organizations.

\section{References}

Anbar, A., Karabıyık, L., \& Eker, M. (2008). Work Related Factors that Affect Burnout among Accounting and Finance Academicians. The Journal of Industrial Relations and Human Resources, 10(4), 110-137. http://dx.doi.org/10.4026/1303-2860.2008.0087.x

Anca, M. (2009). New approaches of the concepts of human resources. Human Resource Management and Strategic Human Resource Management.

Attaianese, E., \& Duca, G. (2012). The human component of sustainability: a study for assessing "human performances" of energy efficient construction blocks. Work, 2141-2146.

Bruch, H., \& Ghoshal, S. (2003). Unleashing Organisational Energy. MIT Sloan Management Review, 45(1), 45-51.

Collins, R. (1981). On the micro-foundations of macrosociology. American Journal of Sociology, 86, 984-1014. http://dx.doi.org/10.1086/227351

Collins, R. (1993). Emotional energy as the common denominator of rational action. Rationality and Society, 5, 203-230. http://dx.doi.org/10.1177/1043463193005002005

Cross, R., Baker, W., \& Parker, A. (2003). What creates energy in organisations? MIT Sloan Management Review, 44(4), 51-56.

Dubois, C. L. Z., \& Dubois, D. A. (2012). Strategic HRM as social design for environmental sustainability in organization. Human Resource Management, 51(6), 799-826. http://dx.doi.org/10.1002/hrm.21504

Frijda, N. H. (1988). The laws of emotion. American Psychologist, 43, 349-358. http://dx.doi.org/10.1037/0003-066X.43.5.349

Fritz, C., Lam, C. F., \& Spreitzer, G. M. (2011). It is the little things that matter: an examination of knowledge workers' energy management. Retrieved from http://www.neeley.tcu.edu/uploadedFiles/Academic_Departments/Management/Its_the_Little_Things_That Matter.pdf

Gonzalez, R. R., Mclellan, T. M., Withey, W. R., Chang, S. K., \& Pandolf, K. B. (1997). Heat strain models applicable for protective clothing systems: comparison of core temperature response. Journal of Applied Physiology, 83, 1017-1032.

Hart, S. L., \& Milstein, M. B. (2003). Creating sustainable value. Academy of Management Executive, 17(2), 56-69. http://dx.doi.org/10.5465/AME.2003.10025194

Holman, D. (2003). Phoning in sick? An overview of employee stress in call centres. Leadership and Organization Development Journal, 24(3), 123-130. http://dx.doi.org/10.1108/01437730310469543

Kamochea, K. et al. (2012). New directions in the management of human resources in Africa. The International Journal of Human Resource Management, 2825-2834. http://dx.doi.org/10.1080/09585192.2012.671504

Kearney, A. T. (2009, February). Companies with a commitment to sustainability tend to outperform their peers during the financial crisis. Retrieved from http://www.atkearney.com/index.php/News-media/companies-with-a-commitment-to-sustainability-tend-tooutperform-their-peers-during-the-fi nancial-crisis.html

Kell, G., \& Lacy, P. (2010). Study: Sustainability a priority for CEOs. Bloomberg Businessweek. Retrieved from http://www.businessweek.com/ managing/content/jun2010/ca20100624_678038.htm

Laszlo, C., \& Zhexembayeva, N. (2011). Embedded sustainability: The next big competitive advantage. Sheffi eld, UK: Greenleaf Publishing. 
Loehr, J., \& Schwarts, T. (2001). The Making of a Corporate Athlete. Harvard Business Review, January, 120-128.

Loehr, J., \& Schwartz, T. (2003). The Power of Full Engagement. New York: The Free Press.

Lounsbury, J. W., Gibson, L. W., \& Hamrick, F. L. (2004). The development and validation of a person logical measure of work drive. Journal of Business and Psychology, 18(4), 427-451. http://dx.doi.org/10.1023/B:JOBU.0000028445.29004.d1

Quinn, R. W. et al. (2012). Building a Sustainable Model of Human Energy in Organizations: Exploring the Critical Role of Resources. The Academy of Management Annals, 6(1), 337-396. http://dx.doi.org/10.1080/19416520.2012.676762

Quinn, R. W., \& Dutton, J. E. (2005). Coordination as energy-in-conversation. Academy of Management Review, 30(1), 36-57. http://dx.doi.org/10.5465/AMR.2005.15281422

Ryan, R. M., \& Frederick, C. (1997). On energy, personality, and health: Subjective vitality as a dynamic reflection of well-being. Journal of Personality, 65, 529-566. http://dx.doi.org/10.1111/j.1467-6494.1997.tb00326.x

Schippers, M. C., \& Hogenes, R. (2011). Energy management of people in organizations: a review and research agenda. Journal of Business and Psychology, 26(2), 193-203. http://dx.doi.org/10.1007/s10869-011-9217-6

Schiuma, G., Mason, S., \& Kennerley, M. (2011). Energy at work: a look at generating a vital commodity for success at work today. Retrieved from www.som.cranfield.ac.uk/som/research/centres/cbp/

Spreitzer, G. M., \& Grant, T. (2011). Helping students manage their energy: taking their pulse with the energy audit. Journal of Management Education. Retrieved from http://jme.sagepub.com/

Srinivasan, M. S. (2012). Management of Human Energies. Retrieved from http://fdi.sasociety.in/cms/index.php\%5D

Steers, R. M., Mowday, R. T., \& Shapiro, D. L. (2004). The future of work motivation theory. Academy of Management Review, 29(3), 379-387.

Taylor, M. T. S., \& Casey, A. (2010). Experiencing energy at work: A mixed methods study of how individuals experience energy in their work. 2010 AHRD International Research Conference in the Americas, Paper \# 240.

Taylor, M. T. S., \& Casey, A. (2011). Defining energy at work: How energy at work has been and may be defined. 2011 AHRD International Research Conference in the Americas, Paper \# 097.

Taylor, M., Schwandt, D. R., \& Casey, A. (2012). Energy and learning at work: the importance of energy. Retrieved from http://www2.warwick.ac.uk/fac/soc/wbs/conf/olkc/archive/olkc6/papers/id_233.pdf

Trudel, J. M. (2009). International human resources management: a new challenge. Portuguese Journal of Management Studies, XIV(2). Retrieved from http://pascal.iseg.utl.pt/ pjms/files/2009International_human_resources_management-a_new_challenge.pdf

\section{Copyrights}

Copyright for this article is retained by the author(s), with first publication rights granted to the journal.

This is an open-access article distributed under the terms and conditions of the Creative Commons Attribution license (http://creativecommons.org/licenses/by/3.0/). 